Check for updates

Cite this: RSC Adv., 2017, 7, 22909

Received 23rd January 2017

Accepted 18th April 2017

DOI: 10.1039/c7ra00995j

rsc.li/rsc-advances

\section{Thiourea catalysed reduction of $\alpha$-keto substituted acrylate compounds using Hantzsch ester as a reducing agent in water $\dagger$}

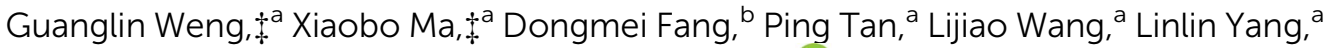 \\ Yuanyuan Zhang, ${ }^{a}$ Shan Qian ${ }^{\star a}$ and Zhouyu Wang (D) *a
}

The first method for the reduction of $\alpha$-keto substituted acrylate compounds by Hantzsch ester in water under the catalysis of thiourea has been developed. The products were isolated in moderate to high yields (38-95\%). These products are important intermediates in the synthesis of a series of natural products and other biologically active molecules.
$\beta$-Keto esters are important intermediates in organic synthesis, ${ }^{1-5}$ and they have been extensively used in the synthesis of a series of natural products and other biologically active molecules such as coumarin derivatives 1 (ref. 6) (potent TNF- $\alpha$ inhibitors), pyrazolo[1,5- $a$ ]pyrimidin-7(4H)-ones 2 (ref. 7) (potent inhibitors of hepatitis $\mathrm{C}$ virus polymerase), cambinol analogues 3 (ref. 8) (isoenzyme inhibitors of the sirtuin family of protein deacetylases), and 4 (ref. 9) (potent prostate cancer antigen-1 inhibitors) (Fig. 1).

Many efforts have been made to achieve efficient preparation of these scaffolds. ${ }^{10-21}$ Two general syntheses of $\beta$-keto esters include (i) acylation of ketones or carboxylic esters by acyl halides or esters ${ }^{22}$ and (ii) acylation of acetylacetone or ethyl

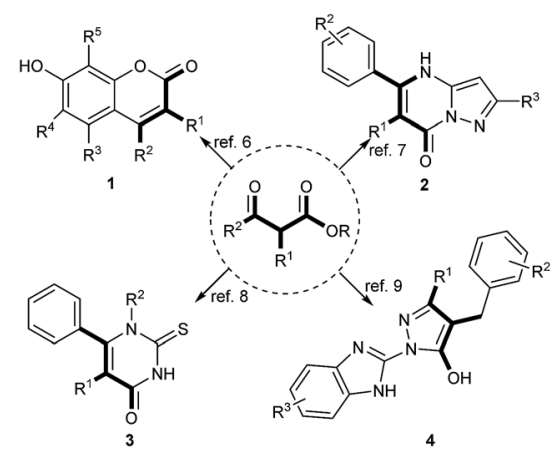

Fig. 1 Synthetic applications of $\beta$-keto esters.

${ }^{a}$ Department of Chemistry, Xihua University, Chengdu, 610039, China. E-mail: zhouyuwang77@gmail.com; qians33@163.com; Fax: +86-28-8772-3006; Tel: +8628-8772-9463

${ }^{b}$ Chengdu Institute of Biology, Chinese Academy of Sciences, Chengdu, 610041, China $\dagger$ Electronic supplementary information (ESI) available. See DOI: $10.1039 / \mathrm{c} 7 \mathrm{ra} 00995 \mathrm{j}$

\$ These authors contributed equally to this work and should be considered co-first authors. acetoacetate and their substituted derivatives by halides or esters followed by base promoted cleavage of a carbonyl group. ${ }^{23,24}$ Recently, Heck reaction between Baylis-Hillman adducts and various aryl sources has been developed as a very attractive alternative method for syntheses of $\beta$-keto esters. ${ }^{25-27}$ In principle, the reduction of Knoevenagel condensation adducts could be an efficient method for the preparation of $\beta$ keto esters. However, it has been barely reported (Scheme 1).

In recent years, Hantzsch esters and their related organic hydride donors have been widely utilized in the reduction of a variety of compounds containing $\mathrm{C}=\mathrm{C}, \mathrm{C}=\mathrm{N}$ and $\mathrm{C}=\mathrm{O}$ unsaturated groups ${ }^{28,29}$ We reported the first example of catalyst free transfer hydrogenation of $\mathrm{C}=\mathrm{C}$ with Hantzsch ester in water. ${ }^{30}$ A series of alkenes conjugated with strong electronwithdrawing groups such as nitrile, ester and nitro could be reduced to the corresponding products in water with excellent yields. More recently, we reported a base promoted cascade protocol for the preparation of reduced Knoevenagel condensation products in water. ${ }^{31}$ However, the $\alpha$-keto substituted acrylate compounds could not be reduced for high yield (35\%)
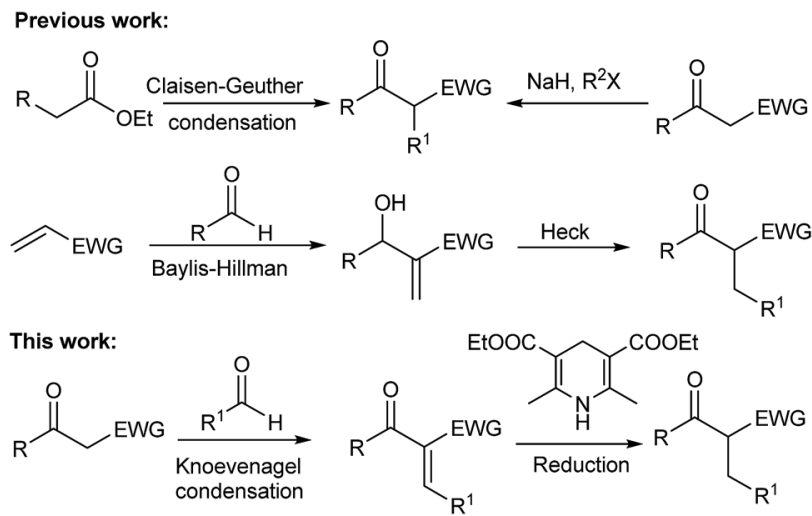

Scheme 1 Methods for the preparation of $\beta$-keto esters. 
under the existing reaction conditions. Here in, we wish to report a simple and efficient synthetic method for the reduction of the $\alpha$-keto substituted acrylate compounds by Hantzsch ester in water under the catalysis of thiourea catalysts.

Initially, we found acetic acid could be used as catalyst in the reaction to get a moderate yield at $100{ }^{\circ} \mathrm{C}$ (Table 1 , entry 2 ).

Table 1 Reaction conditions optimization ${ }^{a}$

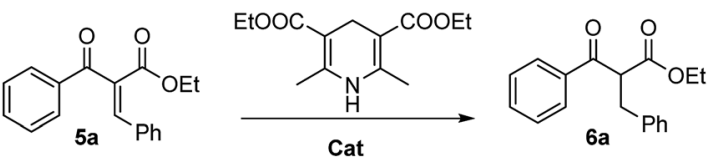<smiles>O[C@H](c1ccc(C(F)(F)F)cc1)[C@H](NC(=S)Nc1cc(C(F)(F)F)cc(C(F)(F)F)c1)c1ccccc1</smiles><smiles>O[C@H](c1ccccc1)[C@H](NC(=S)Nc1cc(C(F)(F)F)cc(C(F)(F)F)c1)c1ccccc1</smiles><smiles>COC(NC(=S)Nc1cc(C(F)(F)F)cc(C(F)(F)F)c1)C(c1ccccc1)c1ccccc1</smiles>

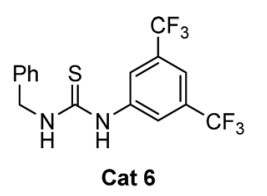

$\underbrace{}_{\text {OेH }}{ }_{\text {Cat } 7}^{\mathrm{Ph}}{ }^{-}{ }^{-1}=0$

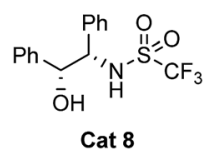

\begin{tabular}{lllllll} 
Entry & Solvent & Catalyst & Cat. (eq.) & Temp (C) & ee $(\%)$ & Yield $^{b}(\%)$ \\
\hline & & & & & & \\
2 & $\mathrm{H}_{2} \mathrm{O}$ & - & - & 100 & - & 35 \\
3 & $\mathrm{H}_{2} \mathrm{O}$ & $\mathrm{CH}_{3} \mathrm{COOH}$ & 0.2 & 100 & - & 60 \\
4 & $\mathrm{H}_{2} \mathrm{O}$ & $\mathrm{CF}_{3} \mathrm{COOH}$ & 0.2 & 100 & - & 40 \\
5 & $\mathrm{H}_{2} \mathrm{O}$ & $\mathrm{CF}_{3} \mathrm{SO}_{3} \mathrm{H}$ & 0.2 & 100 & - & 38 \\
6 & $\mathrm{H}_{2} \mathrm{O}$ & Urea & 0.2 & 100 & - & 40 \\
7 & $\mathrm{H}_{2} \mathrm{O}$ & Thiourea & 0.2 & 100 & - & 56 \\
8 & $\mathrm{H}_{2} \mathrm{O}$ & Cat 1 & 0.2 & 100 & - & 72 \\
9 & $\mathrm{H}_{2} \mathrm{O}$ & Cat 2 & 0.2 & 100 & $<5$ & 93 \\
10 & $\mathrm{H}_{2} \mathrm{O}$ & Cat 3 & 0.2 & 100 & $<5$ & 82 \\
11 & $\mathrm{H}_{2} \mathrm{O}$ & Cat 4 & 0.2 & 100 & $<5$ & 90 \\
12 & $\mathrm{H}_{2} \mathrm{O}$ & Cat 5 & 0.2 & 100 & $<5$ & 80 \\
13 & $\mathrm{H}_{2} \mathrm{O}$ & Cat 6 & 0.2 & 100 & - & 85 \\
14 & $\mathrm{H}_{2} \mathrm{O}$ & Cat 7 & 0.2 & 100 & $<5$ & 62 \\
15 & $\mathrm{H}_{2} \mathrm{O}$ & Cat 8 & 0.2 & 100 & $<5$ & 65 \\
16 & $\mathrm{H}_{2} \mathrm{O}$ & Cat 2 & 0.2 & 80 & $<5$ & 75 \\
$17^{c}$ & $\mathrm{H}_{2} \mathrm{O}$ & Cat 2 & 0.1 & 100 & $<5$ & 82 \\
18 & $\mathrm{H}_{2} \mathrm{O}$ & Cat 2 & 0.2 & 100 & $<5$ & 71 \\
19 & $\mathrm{PhMe}$ & Cat 2 & 0.2 & 100 & $<5$ & 48 \\
20 & $\mathrm{DCM}$ & Cat 2 & 0.2 & 40 & $<5$ & 13 \\
21 & $\mathrm{MeCN}$ & Cat 2 & 0.2 & 84 & $<5$ & 12 \\
22 & $\mathrm{THF}_{23}$ & Cat 2 & 0.2 & 70 & $<5$ & 18 \\
23 & - & Cat 2 & 0.2 & 100 & $<5$ & 25
\end{tabular}

${ }^{a}$ Unless specified otherwise, reactions were carried out with $1.0 \mathrm{mmol}$ of $5 \mathrm{a}$ and $1.0 \mathrm{mmol}$ of Hantzsch ester for 24 hours. ${ }^{b}$ Isolated yield. ${ }^{c}$ The reaction time is 12 hours.
However, no improvement could be achieved when a series of acids with different $\mathrm{p} K_{\mathrm{a}}$ were used in the reaction (Table 1 , entries 3-4). Fortunately, 56\% yield could be obtained when $20 \%$ of thiourea was used in the reaction under the otherwise identical conditions (Table 1 , entry 6). Thus, thiourea derivatives Cat 1-8 were synthesized. The yield of the reduction product could be improved to $72 \%$ when $20 \%$ of Cat 1 was used (Table 1, entry 7). The Cat 2 has the best performance among these new catalysts, and 93\% yield could be achieved when $20 \%$ of Cat 2 was used (Table 1, entry 8). Its diastereomer Cat 3 and enantiomer Cat 4 gave lower yield (Table 1, entries 9 and 10). The hydroxyl and the thiourea parts of Cat 2 seemed very important for the activity of the catalyst. When the hydroxyl protected Cat 5 and the sulfonamides Cat 7 and 8 were used in the reaction, $80 \%, 62 \%$ and $65 \%$ yields could be obtained, respectively (Table 1 , entries 11-14).

We next found $100{ }^{\circ} \mathrm{C}$ is the most suitable temperature for the reaction, only $75 \%$ yield could be obtained when the reaction temperature was decreased to $80{ }^{\circ} \mathrm{C}$ (Table 1 , entry 15). Decreasing the equivalent of the catalyst to $10 \%$, the yield decreased to $82 \%$ (Table 1 , entry 16 ). Shorten the reaction time to 12 hours, the yield dropped to $71 \%$ (Table 1, entry 17 ). Water was found to be the best solvent for the current reduction system since only trace or small amounts of products could be isolated when the reactions were set up in organic solvents such as toluene, dichloromethane, acetonitrile and tetrahydrofuran (Table 1, entries 18-22). Solvent-free made the reaction proceed poorly (Table 1 , entry 23 ). As a result, the best reaction conditions in which the reduction is performed are using $20 \mathrm{~mol} \%$ of Cat 2, Hantzsch ester (1.0 equiv.) in water at $100{ }^{\circ} \mathrm{C}$ for $24 \mathrm{~h}$.

Unfortunately, the products are almost racemate with the catalysis of chiral catalysts Cat 2-5 and Cat 7-8. Two reasons maybe responsible for the results. One is that the $\beta$-keto esters are easy to racemize. The other is the high reaction temperature.

With the optimized reaction conditions in hand, the scope of the thiourea catalyst catalysed reduction was next investigated. A variety of $\alpha$-keto arylacrylate compounds could be reduced to the corresponding products. When the $\mathrm{R}^{2}$ in $\mathbf{5}$ were $p$ substituted phenyls, all the tested substrates could be reduced to the desired products with 76-94\% yields. The substrates with an electron withdrawn group on the para position of the phenyl rings comparing with the substrates with an electron donating groups were easier to be reduced and a higher yield could be obtained (Fig. 2, 6a-g). When the $\mathrm{R}^{2}$ in $\mathbf{5}$ were $o / m$-substituted phenyls, the substrates could be reduced equally at the existing reaction conditions, and almost identical yields were obtained (Fig. 2, $\mathbf{6 h}$ and $\mathbf{6 i}$ ). When the $\mathrm{R}^{2}$ in $\mathbf{5}$ were bulky groups such as 2 naphthyl, the substrate could also be reduced with a $93 \%$ yield (Fig. 2, 6j). The 2-furanyl and 2-thiophenyl could also be used as $\mathrm{R}^{2}$ in the substrate $5,88 \%$ and $77 \%$ yields were obtained when these substrates were used, respectively (Fig. 2, 6k and 6l). The $\mathrm{R}^{1}$ in 5 could be the para electron donating and withdrawn groups substituted phenyl rings, 82-95\% yields were obtained when these substrates were reduced under the existing conditions (Fig. 2, 6m-q). The $o / m$-choro substituted phenyls could also be used as $\mathrm{R}^{1}$ in $\mathbf{5}$, and they could be reduced with $83 \%$ and $85 \%$ yields, respectively (Fig. 2, 6r-s). The relatively bulky rings 

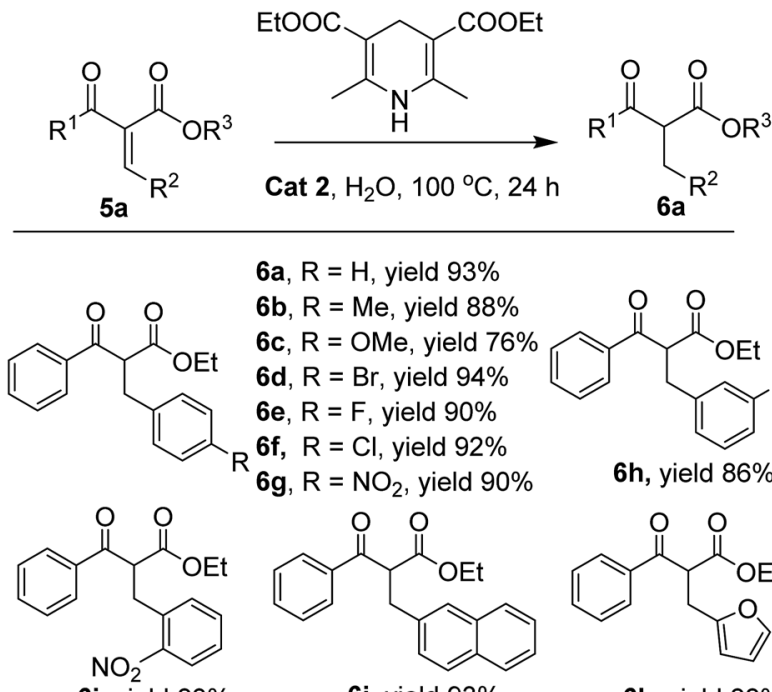

6a, $\mathrm{R}=\mathrm{H}$, yield $93 \%$

6b, $\mathrm{R}=\mathrm{Me}$, yield $88 \%$

6c, $\mathrm{R}=\mathrm{OMe}$, yield $76 \%$

6d, $R=B r$, yield $94 \%$

6e, $R=F$, yield $90 \%$

6f, $\mathrm{R}=\mathrm{Cl}$, yield $92 \%$

$6 \mathrm{~g}, \mathrm{R}=\mathrm{NO}_{2}$, yield $90 \%$

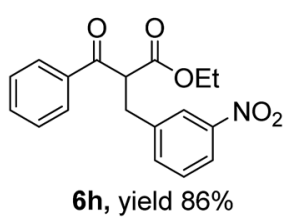

$6 i$, yield $83 \%$<smiles>CCOC(=O)C(Cc1ccc2ccccc2c1)C(=O)c1ccccc1</smiles>

6j, yield 93\%

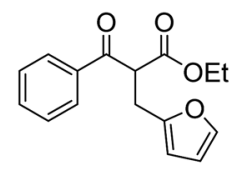

6k, yield $88 \%$<smiles>[H][Z6]1csc(CC(C(=O)OCC)C(=O)c2ccccc2)c1</smiles><smiles>[R]COC(=O)C(Cc1ccccc1)C(=O)c1ccc([R])cc1</smiles>

$6 \mathrm{~m}, \mathrm{R}=\mathrm{Me}$, yield $87 \%$

$6 n, R=O M e$, yield $82 \%$

6o, $R=B r$, yield $90 \%$

6p, $R=F$, yield $95 \%$

$6 q, \quad R=C l$, yield $92 \%$<smiles>CCOC(=O)C(Cc1ccccc1)C(=O)c1ccccc1Cl</smiles>

$6 u$, yield $78 \%$<smiles>[R]C(=O)C(Cc1ccccc1)C(=O)c1ccccc1</smiles><smiles>CCOC(=O)C(Cc1ccccc1)C(=O)c1cccc(Cl)c1</smiles>

6s, yield $85 \%$<smiles>CCOC(=O)C(Cc1ccccc1)C(C)=O</smiles>

$6 v$, yield $38 \%$

6x, $\quad \mathrm{R}=\mathrm{Me}$, yield $89 \%$

$6 \mathrm{y}, \mathrm{R}=i-\mathrm{Pr}$, yield $86 \%$

$6 z, \quad \mathrm{R}=t-\mathrm{Bu}$, yield $85 \%$

6aa, $R=B n$, yield $88 \%$
Fig. 2 Substrate scope of the thiourea Cat 2 catalysed reduction.

and the hetero aromatic ring were tolerated also when they were used as $\mathrm{R}^{1}$ in $\mathbf{5}$, and the corresponding products could be isolated with $75-88 \%$ yields (Fig. 2, 6t-u). Besides Et, other groups such as Me, i-Pr, and Bn could also be used as $\mathrm{R}^{3}$ in $5.85-89 \%$ yields could be obtained when these substrates were reduced under the existing reaction conditions (Fig. 2, 6x-aa). What's more, the $\alpha$-keto alkylacrylate was also can be reduced in the protocol and the ethyl 2-benzoylpentanoate was obtained with $62 \%$ yield (Fig. 2, 6w). However, alkyl group used as $\mathrm{R}^{1}$ in 5 leads to only $38 \%$ yield of the desired product $6 \mathbf{v}$.

Additionally, a gram-scale synthesis of ethyl 2-benzyl-3-oxo3-phenylpropanoate was conducted in the presence of Cat 2 (Scheme 2). The pure product was obtained through column chromatograph with $89 \%$ yield.

Regarding the mechanism of the reduction, we assume that the substrate, Hantzsch ester and the catalyst could be

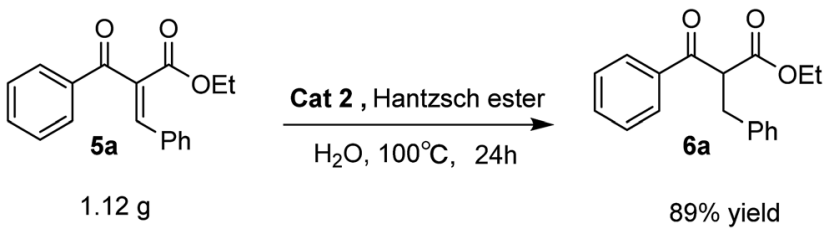

Scheme 2 A gram-scale synthesis of ethyl 2-benzyl-3-oxo-3phenylpropanoate.

dissolved in water at $100{ }^{\circ} \mathrm{C}$. Both the two carbonyl groups of the substrate $\mathbf{5}$ and hydrogen of the Hantzsch ester could be activated by the two $\mathrm{NH}$ of the thiourea and the $\mathrm{OH}$ of catalyst Cat 2, respectively, under the solvent affection of water.

\section{Conclusions}

In summary, we have developed a novel method for the reduction of $\alpha$-keto arylacrylate and alkylacrylate compounds by Hantzsch ester in water under the catalysis of thiourea catalysts. A series of $\alpha$-alkyl- $\beta$-ketoesters were isolated with moderate to high yields. Although the chiral products were fail to obtained, the obvious advantages of this method are high chemoselectivity, water tolerance and mild experimental conditions over the traditional methods such as hydrogenation. Especially, functional groups such as keto, ester, nitro, fluoro, chloro, bromo, furanyl and thienyl are all tolerated by the reaction conditions employed. We believe that this simple, green catalytic protocol provides an alternative way to prepare $\alpha$-alkyl- $\beta$ ketoesters.

\section{Acknowledgements}

We are grateful for the financial supports from the Spring Plan of Ministry of Education (Z2016162), the founds of Sichuan Province (2017JQ0023, 2017NZ0048), the founds of Chengdu City (2015-HM01-00366-SF), the Undergraduate Scientific and Technological Innovation Project, the National Undergraduate Innovation and Entrepreneurship Training Programs of China and The Innovation Fund Of Postgraduate, Xihua University.

\section{Notes and references}

1 J. Yang, W. Li, Z. Jin, X. Liang and J. Ye, Org. Lett., 2010, 12, 5218-5221.

2 C. Yin, W. Cao, L. Lin, X. Liu and X. Feng, Adv. Synth. Catal., 2013, 355, 1924-1930.

3 S. Kotha and E. Manivannan, ARKIVOC, 2003, 67-76.

4 H. J. Cristau, X. Marat, J. P. Vors and J. L. Pirat, Tetrahedron Lett., 2003, 44, 3179-3181.

5 S. Dhiman and S. S. V. Ramasastry, J. Org. Chem., 2013, 78, 10427-10436.

6 J. F. Cheng, M. Chen, D. Wallace, S. Tith, T. Arrhenius, H. Kashiwagi, Y. Ono, A. Ishikawa, H. Sato, T. Kozono, H. Sato and A. M. Nadzan, Bioorg. Med. Chem. Lett., 2004, 14, 2411-2415. 
7 Y. Deng, G. W. Shipps Jr, T. Wang, J. Popovici-Muller, K. E. Rosner, M. A. Siddiqui, J. Duca, A. B. Cooper and M. Cable, Bioorg. Med. Chem. Lett., 2009, 19, 5363-5367.

8 F. Medda, T. L. Joseph, L. Pirrie, M. Higgins, A. M. Z. Slawin, S. Lain, C. Verma and N. J. Westwood, MedChemComm, 2011, 2, 611-615.

9 S. Nakao, M. Mabuchi, T. Shimizu, Y. Itoh, Y. Takeuchi, M. Ueda, H. Mizuno, N. Shigi, I. Ohshio, K. Jinguji, Y. Ueda, M. Yamamoto, T. Furukawa, S. Aoki, K. Tsujikawa and A. Tanaka, Bioorg. Med. Chem. Lett., 2014, 24, 1071-1074.

10 M. Yoshida, K. Fujikawa, S. Sato and S. Hara, ARKIVOC, 2003, 36-42.

$11 \mathrm{~J}$. Christoffers, H. Oertling, P. Fischer and W. Frey, Tetrahedron, 2003, 59, 3769-3778.

12 T. Aoyama, T. Takido and M. Kodomari, Tetrahedron Lett., 2004, 45, 1873-1876.

13 C. V. Galliford and K. A. Scheidt, Chem. Commun., 2008, 1926-1928.

14 H. F. Cui, K. Y. Dong, J. Nie, Y. Zheng and J. A. Ma, Tetrahedron Lett., 2010, 51, 2374-2377.

15 W. Li, J. Wang, X. Hu, K. Shen, W. Wang, Y. Chu, L. Lin, X. Liu and X. Feng, J. Am. Chem. Soc., 2010, 132, 8532-8533.

16 J. Xu, Y. Hu, D. Huang, K. H. Wang, C. Xu and T. Niu, Adv. Synth. Catal., 2012, 354, 515-526.

17 Y. K. Kang, H. H. Kim, K. O. Koh and D. Y. Kim, Tetrahedron Lett., 2012, 53, 3811-3814.

18 M. Vellakkaran, M. M. S. Andappan and N. Kommu, Eur. J. Org. Chem., 2012, 4694-4698.

19 J. Luo, W. Wu, L. W. Xu, Y. Meng and Y. Lu, Tetrahedron Lett., 2013, 54, 2623-2626.

20 W. B. Liu, C. M. Reeves and B. M. Stoltz, J. Am. Chem. Soc., 2013, 135, 17298-17301.
21 Y. Zhao, X. J. Wang, Y. Lin, C. X. Cai and J. T. Liu, Tetrahedron, 2014, 70, 2523-2528.

22 B. O. Linn and C. R. Hauser, J. Am. Chem. Soc., 1956, 78, 6066-6070.

23 S. M. McElvain and K. H. Weber, J. Am. Chem. Soc., 1941, 63, 2192-2197.

24 H. E. Zaugg, R. J. Michaels and E. J. Baker, J. Am. Chem. Soc., 1968, 90, 3800-3808.

25 J. M. Kim, K. H. Kim, T. H. Kim and J. N. Kim, Tetrahedron Lett., 2008, 49, 3248-3251.

26 H.-S. Kim, S. J. Lee, B. Choi and C. M. Yoon, Synthesis, 2012, 44, 3161-3164.

27 K. B. Raju, V. Mari and K. Nagaiah, Synthesis, 2013, 45, 28672874.

28 For reviews about Hantzsch esters: (a) C. Zheng and S. L. You, Chem. Soc. Rev., 2012, 41, 2498-2518; (b) M. Rueping, J. Dufour and F. R. Schoepke, Green Chem., 2011, 13, 1084-1105; (c) Z. Y. Wang and Z. J. Jiang, Asian J. Chem., 2010, 22, 4141-4149; (d) S. L. You, Chem.-Asian J., 2007, 2, 820-827; (e) S. G. Ouellet, A. M. Walji and D. W. MacMillan, Acc. Chem. Res., 2007, 40, 1327-1339.

29 For recent representative paper about Hantzsch esters: (a) L. Qi and Y. Y. Chen, Angew. Chem., Int. Ed., 2016, 55, 13312-13315; (b) K. H. Kim, T. Akiyama and C. H. Cheon, Chem.-Asian J., 2016, 11, 274-279; (c) J. Jung, J. Kim, G. Park, Y. You and E. J. Cho, Adv. Synth. Catal., 2016, 358, 74-80.

30 Q. He, Z. H. Xu, D. H. Jiang, W. S. Ai, R. H. Shi, S. Qian and Z. Y. Wang, RSC Adv., 2014, 4, 8671-8674.

31 T. He, R. H. Shi, Y. M. Gong, G. Y. Jiang, M. Liu, S. Qian and Z. Y. Wang, Synlett, 2016, 1864-1869. 